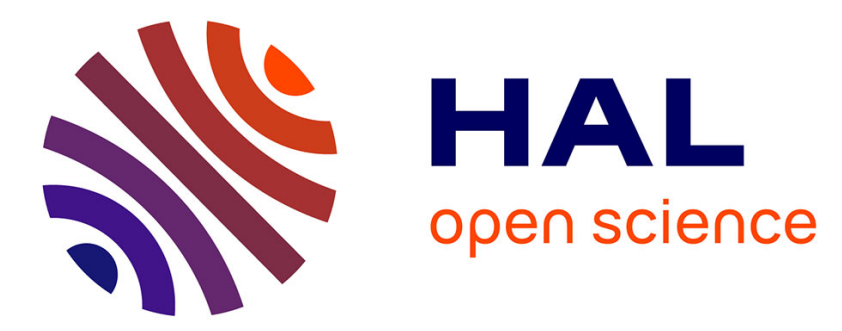

\title{
Prioritization of fish communities with a view to conservation and restoration on a large scale European basin, the Loire (France)
}

Benjamin Bergerot, Emilien Lasne, Thibault Vigneron, Pascal Laffaille

\section{- To cite this version:}

Benjamin Bergerot, Emilien Lasne, Thibault Vigneron, Pascal Laffaille. Prioritization of fish communities with a view to conservation and restoration on a large scale European basin, the Loire (France). Biodiversity and Conservation, 2008, 17 (9), pp.2247-2262. 10.1007/s10531-008-9331-6 . hal-00790023

\section{HAL Id: hal-00790023 \\ https://hal.science/hal-00790023}

Submitted on 19 Feb 2013

HAL is a multi-disciplinary open access archive for the deposit and dissemination of scientific research documents, whether they are published or not. The documents may come from teaching and research institutions in France or abroad, or from public or private research centers.
L'archive ouverte pluridisciplinaire HAL, est destinée au dépôt et à la diffusion de documents scientifiques de niveau recherche, publiés ou non, émanant des établissements d'enseignement et de recherche français ou étrangers, des laboratoires publics ou privés.

\section{다(1)(2)}

Distributed under a Creative Commons Attribution - ShareAlikel 4.0 International 


\title{
Prioritization of fish assemblages with a view to conservation and restoration on a large scale European basin, the Loire (France)
}

\author{
B. Bergerot $\cdot$ E. Lasne $\cdot$ T. Vigneron $\cdot$ P. Laffaille
}

\begin{abstract}
The hierarchical organization of important sites for the conservation or the restoration of fish communities is a great challenge for managers, especially because of financial or time constraints. In this perspective, we developed a methodology, which is easy to implement in different locations. Based on the fish assemblage characteristics of the Loire basin (France), we created a synthetic conservation value index including the rarity, the conservation status and the species origin. The relationship between this new synthetic index and the Fish-Based Index allowed us to establish a classification protocol of the sites along the Loire including fish assemblages to be restored or conserved. Sites presenting disturbed fish assemblages, a low rarity index, few threatened species, and a high proportion of non-native species were considered as important for the restoration of fish biodiversity. These sites were found mainly in areas where the assemblages are typical of the bream zone, e.g. with a higher number of eurytopic and limnophilic species. On the contrary, important sites for conservation were defined as having an important conservation potential (high RI, a lot of threatened species, and few nonnatives fish species) and an undisturbed fish assemblage similar to the expected community if habitats are undisturbed. Important sites for conservation were found in the Loire basin's medium reaches which host assemblages typical for the grayling and the barbell zones, e.g. with a higher number of rheophilic species. The synthetic
\end{abstract}

B. Bergerot $(\bowtie) \cdot$ E. Lasne $\cdot$ P. Laffaille ERT 52-Bâtiment 25 'biodiversité fonctionnelle et gestion des territoires', University of Rennes 1, 1er étage, Campus Beaulieu, 35042 Rennes Cedex, France e-mail: bergerot@mnhn.fr

E. Lasne

e-mail: emilien.lasne@univ-rennes1.fr

P. Laffaille

e-mail: pascal.laffaille@univ-rennes1.fr

T. Vigneron

Conseil Supérieur de la Pêche, Délégation Régionale 2, 84 rue de Rennes,

35510 Cesson Sevigne, France

e-mail: thibault.vigneron@onema.fr 
conservation value index could be adapted and completed with other criteria according to management priorities and capacities.

Keywords Hierarchical organization - Ichthyofauna · Disturbance ·

Rarity index $\cdot$ Origin index $\cdot$ Conservation status

\section{Introduction}

Biodiversity loss in freshwater ecosystems is an increasing phenomenon, mainly due to human activity (Abell 2002). The main causes are habitat destruction and defragmentation (Cuizhang et al. 2003), exotic species introduction (Saunders et al. 2002; Copp et al. 2005), and global climate change impacts (Cuizhang et al. 2003; Lévêque et al. 2005). Aquatic ecosystems are particularly concerned by the loss of biodiversity (Ricciardi and Rasmussen 1999; Gibbs 2000; Saunders et al. 2002; Dawson et al. 2003), especially due to the increase in irrigation needs, industries and private use (Szöllosi-Nagy et al. 1998) but also due to pollution (Lima-Junior et al. 2006). Freshwater fish are one of the most threatened taxonomic groups (Darwall and Vié 2005) because of their high sensitivity to the quantitative and qualitative alterations of aquatic habitats (Laffaille et al. 2005; Oberdorff et al. 2002). As a consequence, they are often used as bioindicators for the assessment of water quality, river network connectivity or flow regime (Chovanec et al. 2003). Today, fish diversity and associated habitats management is a great challenge (Dudgeon et al. 2006).

Two major management actions can be envisaged: habitat conservation and restoration. Conservation consists mainly in the protection of the environment (with the associated species) threatened by external factors (Allan and Flecker 1993) notably for the preservation of species with a high conservation value. Conversely, restoration is the reconsitution of a damaged environment (Young 2000). Unfortunately, even in countries where public opinion is sensitive to environmental protection and to sustainable development, financial, political and logistical means for the management of natural spaces are limited (Aronson et al. 2006). As a consequence, methods must be developed to help managers target important sites for conservation and biodiversity restoration (Das et al. 2006; Pawar et al. 2007). Generally, important sites for maintaining biodiversity are identified and organised with the help of biological and conservation indices (Turpie 1995; Margules and Pressey 2000; Myers et al. 2000). According to Darwall and Vié (2005), the prioritization of conservation and restoration areas can be based on several criteria such as specific richness (Heino 2002; Maes et al. 2005), species abundance (Gotelli and Colwell 2001), their vulnerability (Abellan et al. 2005), irreplaceability or their rarity (Williams et al. 1996; Sólymos and Fehér 2005; Carwardine et al. 2007).

In this study we developed a methodology to help decision making in the management of habitats and species by taking into account not only one but several aspects of the conservation value. To illustrate this, we built a hierarchical typology in one of the largest West European wetland systems, the Loire basin (France). We studied the distribution of fish biodiversity through the use of a range of indices. The combination of these complementary indices allowed us to create a new synthetic index, which was compared to the fish communities disturbance index (FBI) developed by Oberdorff et al. (2002). On this basis, priority sites where the fish communities and their habitats should be conserved or restored were identified. 


\section{Materials and methods}

The study area

The Loire basin is one of the largest in Western Europe (Fig. 1). It drains $115,120 \mathrm{~km}^{2}$, which approximates to one fifth of France's surface. The main river is 1,012 km long and has its source at an altitude of 1,048 m. The Loire river and its main tributary the Allier are less regulated and maintain a better degree of connectivity than most of the others where dams and levees construction may greatly disturb the natural flows.

Data set

The data set analysed in this study was provided by the French Superior Council of Fisheries (ONEMA). This data set came from a group of sites distributed throughout the Loire basin sampled annually between 1995 and 2003. Samples were obtained by electrofishing whilst wading in shallow waters or boating in deeper waters (for more details see Oberdorff et al. 2001; Oberdorff et al. 2002). The combination of these methods enabled a realistic assessment of species presence or absence (Seegert 2000; Oberdorff et al. 2001; Ibarra et al. 2005). The study integrates data from 108 sites distributed throughout the study area that were sampled in each of the 9 sampling years (Fig. 1).

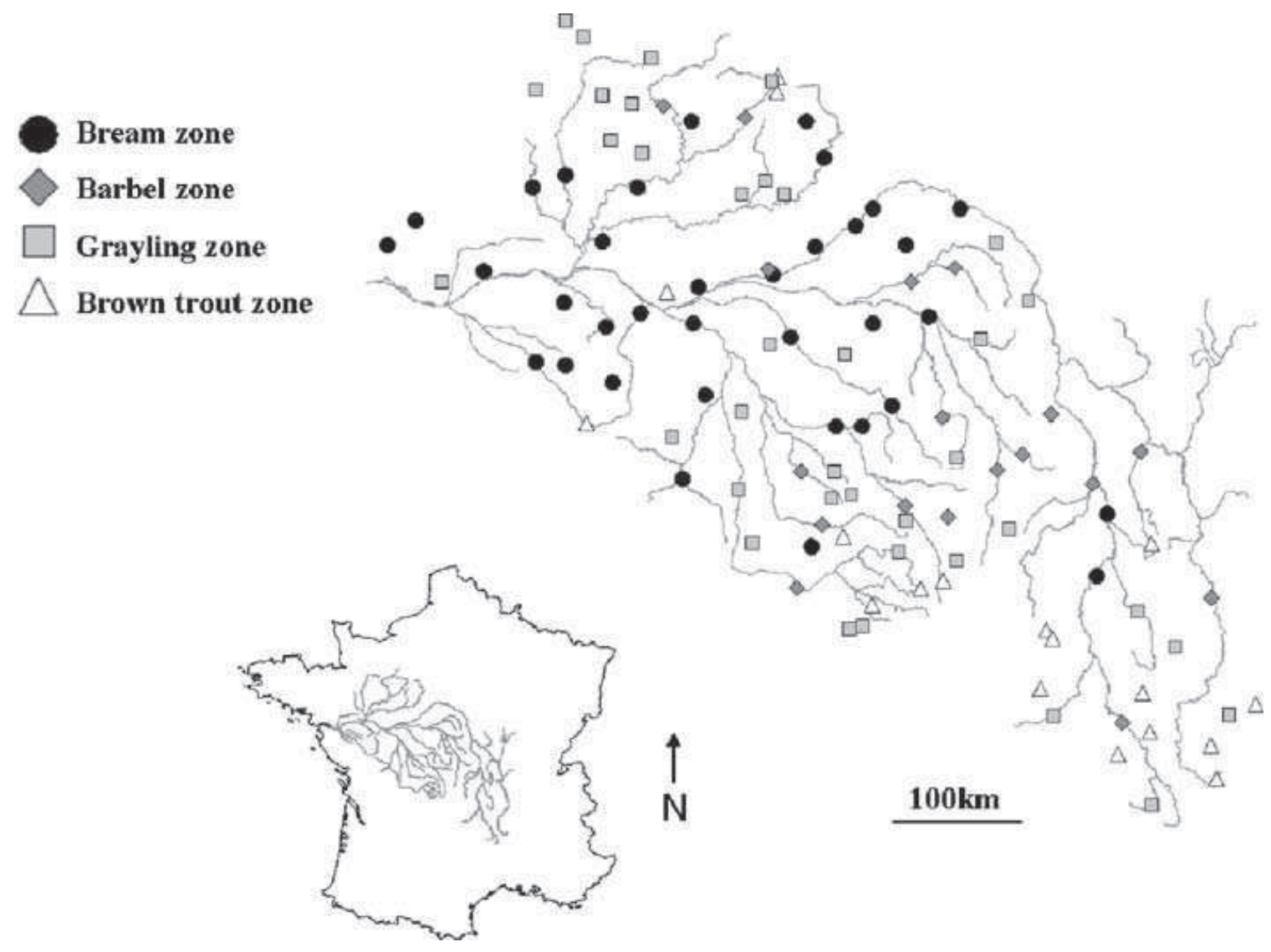

Fig. 1 Map and localisation of the Loire river basin and the sampling sites. Clusters of sites identified by the SOM procedure (see Lasne et al. 2007a) are indicated by various symbols and colours. NB: Only the main tributaries of the basin are shown on the map for better legibility 
Under the assumption that fish are efficient indicators of changes in environmental conditions, in particular hydrological flow (Chovanec et al. 2003; Aarts and Nienhuis 2003; Welcomme et al. 2006), sampling sites were classified into four types corresponding to the four types of the Huet zonation (1959) on the basis of their specific fish assemblage (Fig. 1). This author identified four fish zones in western European rivers in relation with environmental features (slope and width) and the associated fish fauna. They could be characterized by the brown trout (Salmo trutta fario), the grayling (Thymalus thymalus), the barbel (Barbus barbus) and the bream (Abramis brama) in a downstream direction. Upstream zones are characterized by salmonids and small rheophilic species whereas downstream reaches are mainly characterized by eurytopic and limnophilic species.

\section{Indices}

There are many ways to assess the conservation value of assemblages (Darwall and Vié 2005). As a consequence there is an increasing number of indices in the literature that use various criteria to characterize the assemblages. The objective of this study was to develop a method that enabled us to take into account several aspects of an assemblage's conservation value. Thus, we selected different indices to combine various criteria. Firstly, we chose a rarity index that takes into account the rarity of species (Fattorini 2006). Secondly, since most ecosystems are today threatened by the introduction of exotic species, we created an index that takes into account the origin (i.e. native $v s$ exotic) of the species. Thirdly, we used an index of the species conservation status. Eventually, we used an index of fish assemblage's perturbation (Oberdorff et al. 2002). Calculation of the indices was made for each sampling site and the average over the nine sampling years was used.

\section{Rarity index (RI)}

This index measures the rarity of the fish species and it is based on a weight attributed to each of them (Fattorini 2006). This index corresponds to a restricted range species index. To calculate the rarity index (RI), we weighted species by the inverse of their geographic range size (represented here by the occurrence frequency).

$$
R I=\sum_{i=1}^{S} \frac{P^{-1}}{S}
$$

where $\mathrm{S}$ is the total number of species in a sample (site), and $P$ is the total number of samples occupied by each species. The rarity index is high when the sample is composed only of scarce species and minimum (tends towards zero) when there are few scarce species in the sample. The rarity index was modified to vary between 0 and 1 by dividing it by its maximal value over the nine years.

Native and non-native species (origin index, OI)

An origin index was used on the basis of a ratio between the number of non-native and native species of the Loire basin for each site, according to the definition of Copp et al. (2005). 


$$
O I=\left|1-\frac{\text { Number of non native species }}{\text { Number of native species }}\right|
$$

The initial index was modified by $|1-X|$, where $X$ is the value of the index (number of non-native species/ number of native species). By doing this, the variations of the OI index are the same than the others indices. Thus, the lower the ratio, the more native species are present on the site in comparison to non-native species (the ratio is null when there are no non-native species), so the OI index tends to 1 . Inversely, the greater the ratio, the less native species are present on the site in comparison to non-native species (the ratio tends to one), so the OI index tends to 0 .

\section{Biodiversity conservation concern (BCC)}

This index allows two types of information to be used concomitantly: the conservation status of each species belonging to a given assemblage (through the protection status) and the total species richness of that assemblage (Fattorini 2006). The BCC can be calculated as :

$$
B C C=\frac{\sum_{i=1}^{K} \frac{\alpha_{i} A_{i}}{S}-1}{\alpha_{\max }-1}
$$

where $\alpha_{i}$ is the $i$ th category of endangerment of the species, with $\alpha_{4}>\alpha_{3}>\alpha_{2}>\alpha_{1}=1$. $\mathrm{A}_{\mathrm{i}}$ represents the number of species included in the $i$ th category and $S$ the total number of species in the site sample $\left(S=\sum_{i=1}^{K} A_{i}\right) . K$ is the number of extinction risk categories. For the calculation of the weight of each species (Table 1), we used the operator $2^{\mathrm{n}}$ following the Fattorini method (2006) corresponding to a geometric series $2^{\mathrm{n}}$. Thus $\alpha_{1}=1, \alpha_{2}=2$, $\alpha_{3}=4$, and $\alpha_{4}=8$.

We used the "Fauna-Flora-Habitats" directive (21/5/1992 93/43/CEE directive) and Berne Convention (1979) to calculate this index. They were chosen because they take into account all the species included in the data set. However, other conventions or directives could be chosen according to the management priorities e.g. the UICN (International Union for the Conservation of Nature) Red List of threatened Species.

The BCC index varies between 0 (when the sampling site does not include protected species) and 1 (when the sampling site includes only protected species in the highest category of extinction risk). A sampling site which only, includes protected species but in different categories would score a value lower than 1 .

\section{Fish based index (FBI)}

This fish disturbance index involves a series of metrics based on the structure and the function of aquatic assemblages (fish or invertebrate) that give reliable signals of river conditions to calculate an index score at each site, which is then compared to the score expected in the absence of stress. It includes metrics such as species richness, species composition, trophic structure, total fish abundance and individual fish condition (see Oberdorff et al. 2002 for more details). The FBI varies between 0 (the observed population is the same as the reference population), and infinity (the observed population is very 
Table 1 Species list; origin: $\mathrm{N}=$ native, $\mathrm{NN}=$ non-native; convention: $\mathrm{FFH}=$ Fauna Flora and Habitats Convention and weight of each species. The figure in roman typeface shows the protection status (registered in the different convention annexes)

\begin{tabular}{|c|c|c|c|c|c|c|c|}
\hline Family & Genus & Species & Common name & Origin & FFH & $\begin{array}{l}\text { Berne } \\
\text { convention }\end{array}$ & Weight \\
\hline Anguillidae & Anguilla & anguilla & Eel & $\mathrm{N}$ & & & 1 \\
\hline Centrarchidae & Lepomis & gibbosus & Pumpkinseed & $\mathrm{NN}$ & & & 1 \\
\hline Cobitidae & Barbatula & barbatula & Stone loach & $\mathrm{N}$ & & & 1 \\
\hline Cottidae & Cottus & gobio & Bullhead & $\mathrm{N}$ & II & & 2 \\
\hline \multirow[t]{16}{*}{ Cyprinidae } & Abramis & brama & Bream & $\mathrm{N}$ & & & 1 \\
\hline & Alburnoides & bipunctatus & Stream bleak & $\mathrm{N}$ & & III & 2 \\
\hline & Alburnus & alburnus & Bleak & $\mathrm{N}$ & & & 1 \\
\hline & Barbus & barbus & Barbel & $\mathrm{N}$ & V & & 2 \\
\hline & Carassius & auratus & Gibel carp & NN & & & 1 \\
\hline & Chondrostoma & nasus & Nase & $\mathrm{N}$ & & III & 2 \\
\hline & Chondrostoma & toxostoma & Soiffe & $\mathrm{N}$ & II & III & 4 \\
\hline & Cyprinus & carpio & Carp & NN & & & 1 \\
\hline & Gobio & gobio & Gudgeon & $\mathrm{N}$ & & & 1 \\
\hline & Leuciscus & cephalus & Chub & $\mathrm{N}$ & & & 1 \\
\hline & Leuciscus & leuciscus & Dace & $\mathrm{N}$ & & & 1 \\
\hline & Phoxinus & phoxinus & Minnow & $\mathrm{N}$ & & & 1 \\
\hline & Rhodeus & sericeus amarus & Bitterling & $\mathrm{N}$ & II & III & 4 \\
\hline & Rutilus & rutilus & Roach & $\mathrm{N}$ & & & 1 \\
\hline & Scardinius & erythrophtalmus & Rudd & $\mathrm{N}$ & & & 1 \\
\hline & Tinca & tinca & Tench & $\mathrm{N}$ & & & 1 \\
\hline Esocidae & Esox & lucius & Pike & $\mathrm{N}$ & & & 1 \\
\hline Gadidae & Lota & lota & Burbot & $\mathrm{N}$ & & & 1 \\
\hline \multirow[t]{2}{*}{ Gasterosteidae } & Gasterosteus & aculeatus & $\begin{array}{r}\text { Three-spined } \\
\text { stickleback }\end{array}$ & $\mathrm{N}$ & & & 1 \\
\hline & Pungitius & pungitius & $\begin{array}{l}\text { Ten-spined } \\
\text { stickleback }\end{array}$ & $\mathrm{N}$ & & & 1 \\
\hline Ictaluridae & Ameiurus & melas & Black bullhead & NN & & & 1 \\
\hline \multirow[t]{3}{*}{ Percidae } & Gymnocephalus & cernuиs & Ruffe & $\mathrm{N}$ & & & 1 \\
\hline & Perca & fluviatilis & Perch & $\mathrm{N}$ & & & 1 \\
\hline & Stizostedion & lucioperca & Pikeperch & NN & & & 1 \\
\hline Petromyzontidae & Lampetra & planeri & Brook lamprey & $\mathrm{N}$ & II & III & 4 \\
\hline \multirow[t]{3}{*}{ Salmonidae } & Salmo & salar & Salmon & $\mathrm{N}$ & II & and $\mathrm{V}$ & III \\
\hline & 8 & & & & & & \\
\hline & Salmo & trutta fario & Brown trout & $\mathrm{N}$ & & & 1 \\
\hline Thymallus & thymallus & Grayling & $\mathrm{N}$ & V & III & 4 & \\
\hline
\end{tabular}

different from the reference population). As for the OI index, the FBI index was modified by $|1-\mathrm{X}|$ where $\mathrm{X}$ is the value of the index, and weighed to vary between 0 (high disturbance) and 1 (low disturbance). 
The sites with high IR, BCC, OI and FBI were considered as having a high conservation value with low perturbations and should be conserved. Inversely, sites with low IR, BCC, OI and FBI were considered as priority sites for restoration. This method enabled us to organize data into a hierarchical structure according to information that was really available in the study area and to select sites for conservation and restoration management. Finally, indices (IR, BCC, and OI) were added and compiled in a synthetic index Q. The Q value varied between 0 (when the three indices had a low conservation value) to 3 (when the three indices had a high conservation value). The value of each index between Huet zones, were compared using Kruskal-Wallis tests and Dunn's post test. In order to examine the relative proportion of each of the four assemblages defined on the basis of the Huet zonation (1959), the first and fourth quartile of Q and FBI, among the four assemblage types, were compared using G-tests.

The synthesis between the Q index and the disturbance index FBI gave a definition of important areas for conservation and restoration on the scale of the Loire basin. In that way, sites to be restored in priority belonged to the first quartile of the FBI and Q indices. Thus they had a high level of disturbance (low FBI), more non-native species than native species (low OI), few scarce species (low RI) and few threatened species (low BCC). Inversely, sites to be conserved in priority belong to the fourth quartile of the FBI and Q indices. Thus they had a high conservation potential (high rarity, a lot of threatened species, and few non-native species) and few disturbances with an observed population similar to the theoretical population (FBI).

\section{Results}

Fish biodiversity

A total of 12 fish families were sampled which included 32 species (Table 1).

The cyprinids were the most common family represented with 16 species. The stone loach (Barbatula barbatula), gudgeon (Gobio gobio), minnow (Phoxinus phoxinus), chub (Leuciscus cephalus), roach (Rutilus rutilus) and perch (Perca fluviatilis) were ranked as "common" species (i.e. sampled at least once in $>75 \%$ of the sites, Fig. 2). Conversely, the burbot (Lota lota), three-spined stickleback (Gasterosteus aculeatus), salmon (Salmo salar), soiffe (Chondrostoma toxostoma) and grayling were the most scarce species (occurrence frequency $<25 \%$ ). Nine species have a conservation status (Table 1) and three are scarce in the Loire basin (the grayling, the salmon and the soiffe). Five species are nonnatives. The perch is the only common non-native species (occurrence frequency $>50 \%$ ).

Indices

The rarity index (Fig. 3a) increased significantly (Kruskal-Wallis, $N=108, W=74.152$, $P<0.0001$; Dunn's post test), along the longitudinal upstream (brown trout zone)downstream gradient (barbel and bream zones) where the index is the highest. However, there was no difference between fish assemblages in the barbel and bream zones on the basis of the RI. In general, the rarity index was low because there are few scarce species. 


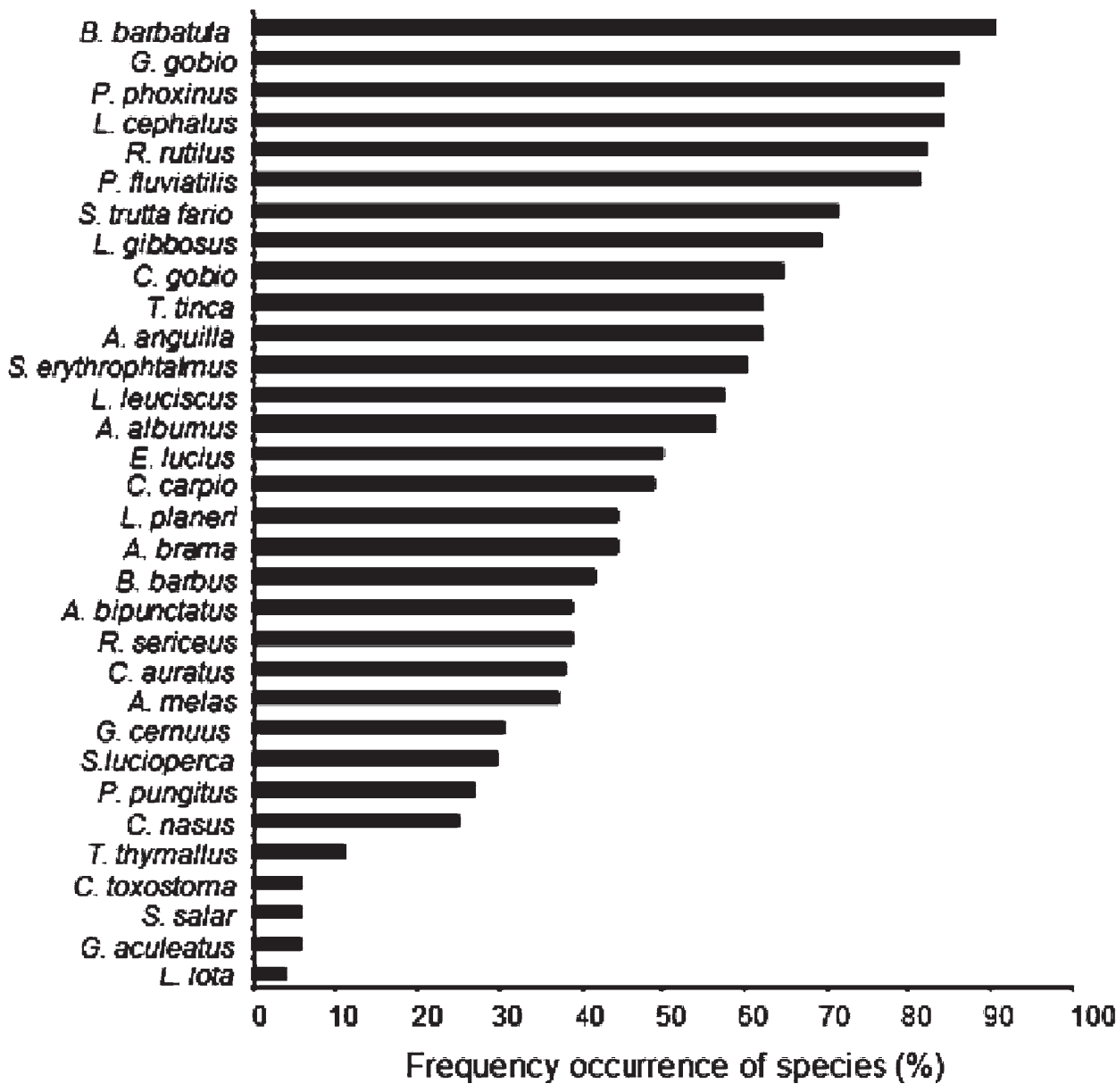

Fig. 2 Occurrence frequency (\%) of each species over the nine sampling years and the 108 sampling sites

The study of the origin index OI (Fig. 3b) showed a significant difference (KruskalWallis, $N=108, W=37.24, P<0.001$, Dunn's post test) between the brown trout and the bream zone according to the upstream-downstream longitudinal gradient. In general, the high values of OI show that fish assemblages included more native species in comparison with non-native species.

The BCC index (Fig. 3c) showed that fish assemblages in medium reaches (grayling and more particularly barbel zones) included significantly more protected species than upstream and downstream reaches (Kruskal-Wallis, $N=108, W=17.85, P<0.001$, Dunn's post test). In general, the BCC index was low because there are few species with a high conservation status in fish assemblages.

The synthetic index Q (Fig. 3d), grouping the BCC, OI and RI indices suggested that sites of the medium areas belonging to the grayling and barbel zones have a particular conservation interest (Kruskal-Wallis, $N=108, W=24.703, P<0.001$, Dunn's pot test).

Eventually, the disturbance index FBI (Fig. 3e) showed a significant upstream-downstream longitudinal gradient (Kruskal-Wallis, $N=108, W=15.658, P<0.05$, Dunn's post test). Sites in downstream reaches were the most disturbed (low FBI value for zone IV), as compared with the upstream reaches.

Sites prioritization for conservation and restoration

Sites with the highest Q index values (fourth quartile) concerned mainly the grayling and barbel zones, whereas the less disturbed sites (i.e. fourth quartile of the FBI index) were 

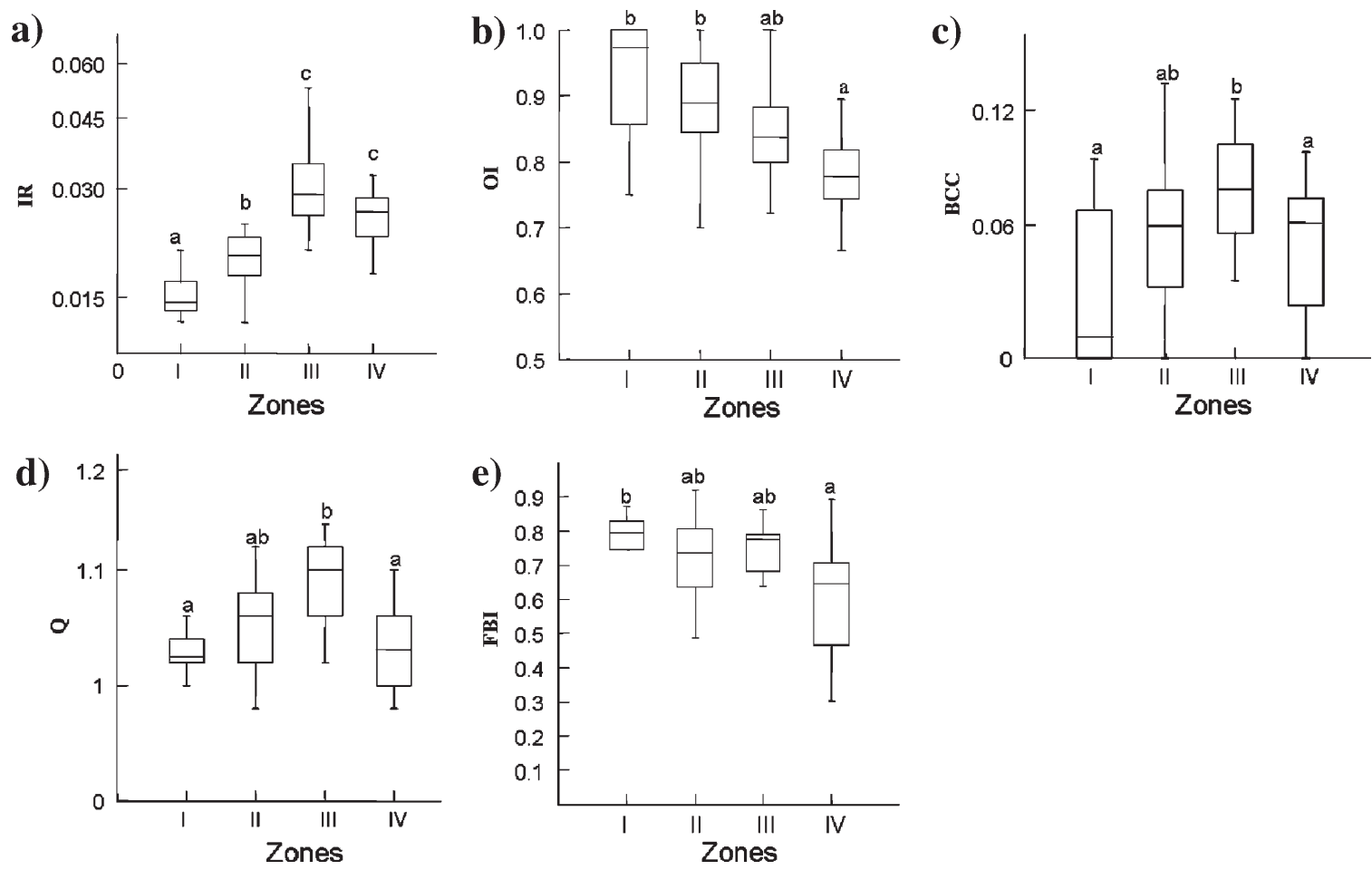

Fig. 3 (a) Rarity Index (RI), (b) Origin Index (OI), (c) Biodiversity Conservation Concern (BCC) index, (d) Synthetic Index (Q) and (e) Fish-Based Index (FBI) according to the Huet zonation (1959). Zones: $\mathrm{I}=$ brown trout, II = grayling, III = barbel, IV = bream. The same letter above bars shows that values are not statistically different (Dunn's post tests; $\alpha=0.05$ ) when Kruskal-Wallis (KW) $P<0.05$

mainly localised in the upstream reaches in the brown trout and grayling zones (G-test, $N=54, \mathrm{ddl}=3, G=9.19, P<0.05$, Table 2). More than half of the least priority sites for conservation (first quartile of the $\mathrm{Q}$ index) and the most disturbed (first quartile of the FBI index) were localised in the bream zone (G-test, $N=56$, ddl $=3, G=1.74$, $P>0.05$, Table 2). FBI is a habitat integrity index, and fish are used as a tool for bioindication, with no consideration for their intrinsic conservation value (for instance, species origin is not taken into account), whereas the $\mathrm{Q}$ index gives no weight to functional aspects of fish but only reflects the conservation value of the assemblages. Finally, sites with high (or low) value of Q index or sites with high (or low) value of FBI index were not the same. Thus the Q and FBI indices supplied complementary information (Table 2). They allow important sites for conservation priorities to be defined as belonging to the

Table 2 Percentage of sites (number of sites) belonging to the first and the last quartile of the synthetic index $\mathrm{Q}$ and the Fish-Based Index (FBI). Zones : I = brown trout zone, II = grayling zone, III = barbel zone, IV = bream zone

\begin{tabular}{lcclll}
\hline & Index Q & & & FBI \\
\cline { 2 - 3 } & First quartile (\%) & Fourth quartile (\%) & & First quartile (\%) & Fourth quartile (\%) \\
\hline Zone I & $18.52(5)$ & $3.71(1)$ & & $14.81(4)$ & $33.34(9)$ \\
Zone II & $25.93(7)$ & $44.44(12)$ & & $25.93(7)$ & $37.04(10)$ \\
Zone III & $0(0)$ & $44.44(12)$ & & $7.41(2)$ & $14.81(4)$ \\
Zone IV & $55.55(15)$ & $7.41(2)$ & & $51.85(14)$ & $14.81(4)$ \\
\hline
\end{tabular}


fourth quartile of the Q index (including species with high conservation value, scarce species, and an large proportion of native species compared with non-native species) and the fourth quartile of the FBI index (sites represented by a few perturbed population, close to the reference population).

After the analysis of sites that belonged to the same zone of each quartile, eleven sites to be conserved were identified (Fig. 4), that we found principally in the grayling and barbel zones (respectively 6 and 4 sites out of 11). No one was found in the bream zone. Inversely, priority sites for restoration actions were defined as sites belonging to the same zone of the first quartile of the Q index (sites including few species with a high conservation value, a high proportion of non-native species compared with native species, and few scarce species) and the first quartile of the FBI index (sites with a population considered as strongly perturbed). On this basis, fourteen sites to be restored were identified (Fig. 4), although three sites were listed in upstream reaches (trout zone), zones to be restored in priority were mainly concentrated in the most downstream reaches of the Loire basin for eight sites.

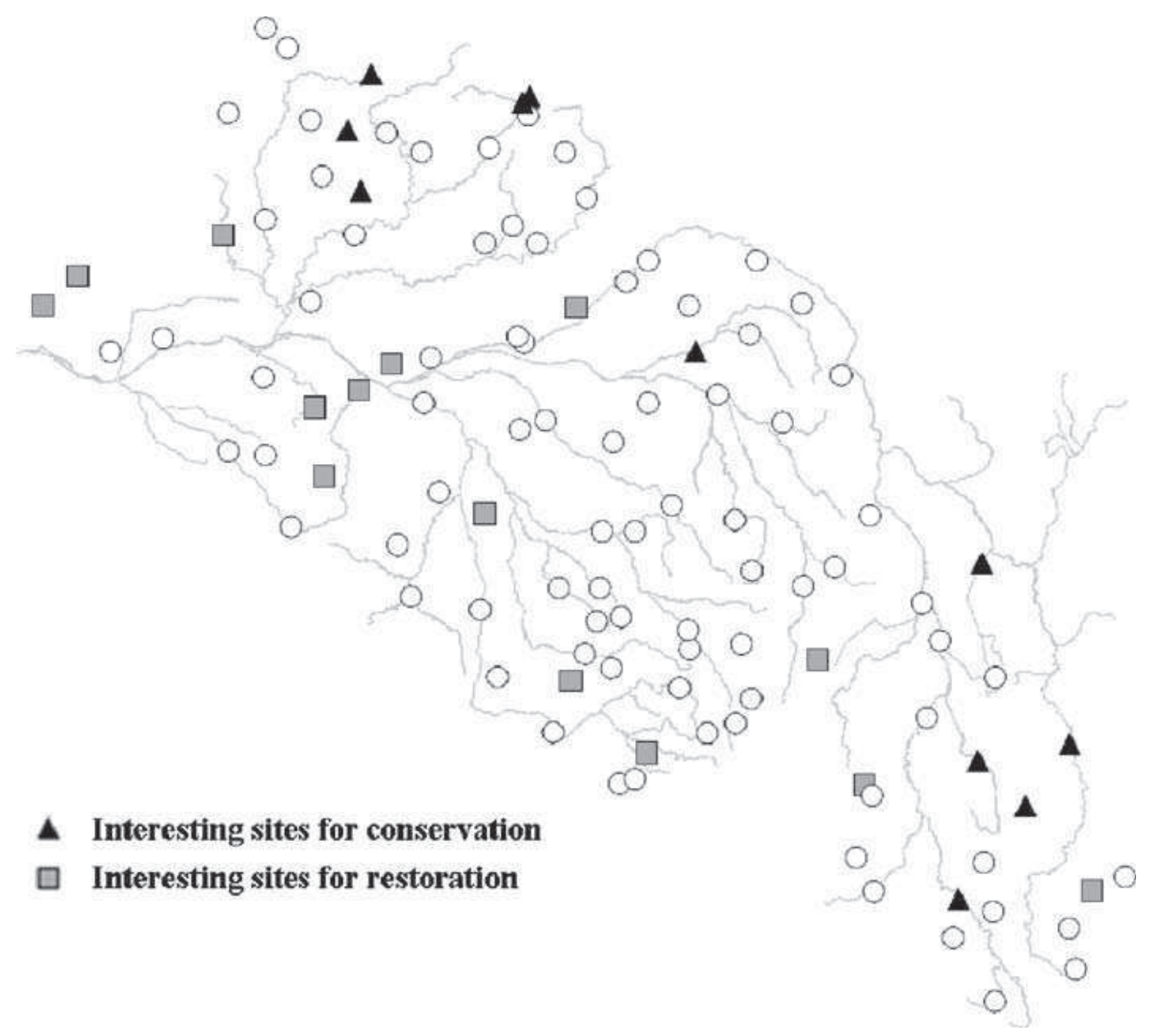

Fig. 4 Map localisation of the priority sites for conservation $(N=11)$ or restoration $(N=14)$ actions along the Loire basin $(N=108)$ according to the synthetic index $\mathrm{Q}$ and the perturbation index FBI 
Thus, according to our criteria, we obtained a spatial segregation between sites to be restored, localised principally in the most downstream reaches, and sites to be conserved, which were, above all, localised in the medium reaches.

\section{Discussion and conclusions}

As regards the ichthyofauna in freshwater habitats, species richness is constrained by the environmental variables, especially the drainage area (Oberdorff et al. 1995) and the distance to the spring (Ibarra et al. 2003). Upper reaches are occupied by a small set of species adapted to cold waters and strong flow such as salmonids. Habitat heterogeneity (including thermic and flow heterogeneity) increases downstream providing a wide range of niches (Guégan et al. 1998) that may be used by a large set of species (Oberdorff et al. 1993; Aarst and Nienhuis 2003). Generally, at a catchment scale, the species richness increases downstream. Because of these natural patterns, the use of the species richness as a crude indicator of the conservation value of fish assemblages is of little relevance, contrary to other taxa such as invertebrates (Canard and Ysnel 2000). On the other hand, the use of indices that give little or no weight to specific richness, such as those used in this study, seems more pertinent.

The index results shows that sites which host a fish assemblage characteristic of the brown trout zone (mainly in headwaters) had a lower rarity index value according to Fattorini (2006) than sites characterized by grayling zone assemblages (mainly in medium reaches) or barbel and bream zone assemblages (mainly in downstream reaches). In other words, the rarity of assemblages increased along the upstream-downstream longitudinal gradient of the fish zonation (Huet 1959; Verneaux 1981).

The ratio between the number of non-native and native species for each site (OI index) showed that brown trout and grayling assemblages include proportionally less non-native species than other assemblages. This result was expected since in the downstream and medium zones, the river's structure (e.g. width, variable depth and the floodplain) supplies a large diversity of micro-habitats that promotes the maintenance of exotic species (Quist et al. 2005). In addition, medium and downstream reaches are often more highly alteredespecially in terms of flow regime-than upstream reaches (Aarts and Nienhuis 2003). Moreover, changes in species composition are often related to flow regulation (Poff et al. 1997; Ward 1998). More precisely, flow regulation in downstream reaches can facilitate the development of exotic species and the exclusion of native species (Saunders et al. 2002), because in general, invasive exotic species are mainly eurytopic (i.e species which tolerate environmental alterations) or limnophilic species (Galat and Zweimüller 2001; Copp et al. 2005). Thus, the higher proportion of non-native species in downstream reaches of the Loire basin may also result from the higher alteration levels. Conversely, undisturbed and semi-natural communities tend to contain few, if any, non-native species (Manchester and Bullock 2000). In upstream reaches, conditions are very rude (low temperatures, high flow velocity) so that the probability that an introduced species would settle is very low.

Today, non-native species introduction, although widely recognized, is one of the main threats for local biodiversity (Saunders et al. 2002). But in this study, relatively few exotic species were sampled suggesting that the Loire basin is not very affected by species introduction. However, sampling at a finer spatial scale (across the floodplain gradient) suggests that exotic species' contribution to the regional pool is greater (Lasne et al. 2007b). These authors show that exotic species prefer lentic conditions available in 
disconnected waterbodies of the large floodplain. Since such waterbodies have not been sampled in this study, it is likely that the OI index difference between upstream and downstream reaches actually is greater.

Consideration of the BCC index was justified by the fact that the attribution of a specific weight for the different species (with, for instance, different conservation status) allows assemblages with a similar specific richness but with different species to receive different conservation values (Fattorini 2006). Our results suggest that medium reaches in the basin represent a main interest. Conversely, species of the bream zones are mainly eurytopic and, by definition, more likely to use a wide range of habitats, including disturbed ones. Appart from species that require different habitats for spawning, nursery and growth (e.g. Pike Esox lucius) or species sensitive to eutrophication (e.g. some limnophilic species), most species inhabiting these reaches are not threatened. Concerning small mountainous regions headwater streams, as suggested by Aarts and Nienhuis (2003), human impacts are generally lower. Thus, species characteristic of the brown trout zone are less likely to be threatened.

However, it is necessary to moderate these conclusions provided by the BCC. Indeed, the allocation system of the weights for each species may be too general. Fattorini (2006), working on butterflies, lists many species (about 70), while this study includes only 32 species. Moreover, the BCC index is sensitive to the use of the different levels of threat to the species. We considered four categories of threats in this study while Fattorini (2006) worked with a great number of species and five threat categories. Eventually, the regular updating of the texts relating to conservation status is necessary and could be a mistake source. For example, some species, which are not included in the protection lists could be taken into account in the calculation of this index, for example the eel (Anguilla anguilla) whose continental stocks have been clearly decreasing since the 1980's (Baisez and Laffaille 2005).

The different indices used in this work showed contrasted patterns in the various assemblage types. Thus, according to Lima-Junior et al. (2006) and Welcomme et al. (2006), our results suggest that the use of a single criterion to assess conservation value of assemblages is hazardous. While each index may be subject to a specific discussion, the combination of various indices is better more accurate in identifying sites of high conservation value. Thus, identification of priority sites for freshwater conservation or restoration, at the Loire basin scale, was realised on the basis of the Q index quartiles in association with the quartiles of the perturbation FBI index developed by Oberdorff et al. (2002). These indices supply complementary information. Therefore, they can be used to specify the sites value in our study.

On the one hand, according to our criteria, priority areas for freshwater conservation perspective were mainly localised in areas characterised by grayling and barbel assemblages. This is consistent with the idea that fish assemblages in the medium reaches are more sensitive to habitat change and host the most endangered fish fauna (Aarts and Nienhuis 2003). On the other hand, sites to be restored in priority were mainly occupied by bream assemblages, i.e. characteristic of the downstream reaches (Figs. 1 and 4). Such results are not surprising because this assemblage type (with a lot of eurytopic species) is the more likely to occur in the most disturbed ecosystems (Aarts and Nienhuis 2003; Lytle and Poff 2004; Lasne et al. 2007a), i.e. in areas that are exposed to high human pressure exerted by population density and intensive farming (Noss 2000). Some atypical sites to be restored exist. In fact, they are near the sea but were identified as sites with high species richness including upstream and downstream indicator species. This may be the result of human activity, which creates direct perturbation on fish communities by the introduction of species, although there are already native species in the basin (example of the brown 
trout for fishing, Hickley and Chare 2004). This could also result from an indirect factor such as the flow regulation that generates a fluctuating lentic/lotic environment along the river (Poff et al. 1997; Cuizhang et al. 2003). However, conversely to other European large systems (Aarts and Nienhuis 2003), the Loire Basin still keeps fish patterns close to those expected on the basis of the Huet zonation (1959) (Lasne et al. 2007a).

It could be very interesting to restore sites which show high perturbation levels and also hold many rare and threatened species but other managers could also choose to restore sites which show medium perturbation but which also hold many rare and threatened species. This selection method might be less expensive and more easily implemented than the restoration of a completely disturbed site, and could result in a better success probability. Whatever way sites are selected, one should remember that rivers are "flood-dependent" ecosystems and the flood plains are part of the river itself (Ward 1998). Thus, care must be taken not only to designate small river sections where the species persists, but to identify the reasons for the reduction in population size and distribution. The designation of catchments, including all the subcatchments (land and water) upstream is necessary and must be negotiated. Of course, river management cannot be limited in space to the scale of a sampling site and an integrative management of the whole basin could be useful to allow fish diversity preservation. Indeed, the linear and continuous nature of rivers implies the consideration of their whole route as well as their associated tributaries (Pringle 2001; Collareis-Pereira and Cowx 2004). A more complete understanding of ecological processes from a landscape perspective, will not only advance the discipline of river ecology, but will also enhance the effectiveness of conservation and restoration initiatives (Ward et al. 2001; Kondolf et al. 2006; Tetzlaff et al. 2007).

Although the choice of criteria could be a controversial question, the aim of this study was to develop a method to prioritize sites on a conservation or restoration viewpoint. So, at a regional scale, the accumulation of criteria such as species richness, endemism and rarity to develop scoring procedures or rank sites indices may suffer from high species or habitat redundancy. Our results suggest that fish management at the biotic zone scale-i.e. according to Huet zonation (1959)_could be a relevant option. In other words, upper catchment protection could provide wide-ranging benefits to downstream habitats provided that the hydrological connectivity is respected.

This hierarchical prioritization method must be finally adapted to each territory's features (adaptive management) but also to the needs and to the capacities of the stakeholders (pragmatic management). But numerous parameters play a part in species composition within a site, which exacerbate the difficulty to evaluate and prioritize hierarchically. For example, Darwall and Vié (2005) document sixteen commonly applied evaluation criteria, including species richness, $\beta$ diversity, scarce species, species threatened status, species endemism or the keystone species. On the one hand, our relatively weak choice in the number of sites constitutes a pragmatic choice to better use financial and human efforts, which are the limiting criteria in the management of aquatic systems (Baisez and Laffaille 2005). One the other hand, if financial means are limited within a territory, we can then take fewer sites into account, as for example an eighth in each of both categories (conservation and restoration).

The consistency between the conclusions of this study and the literature suggests that the site prioritization method developed in this study is relevant and could be adapted in other contexts or with other taxa. This is a dynamic method since it is possible to add or remove indices depending on management targets within the framework of adaptive management. It is also possible to take into account other criteria such as migratory behaviour, or the economic value of fish. 
Acknowledgements We are grateful to the National French Fishing Council (ONEMA) which provided data. The study was supported by DIREN and Region Pays-de-la-Loire and by the Loire-Bretagne Water Agency.

\section{References}

Aarts BGW, Nienhuis PH (2003) Fish zonation and guilds as the basis for the assessment of ecological integrity of large rivers. Hydrobiologia 500:157-178

Abell R (2002) Conservation biology for the biodiversity crisis : a freshwater follow-up. Conserv Biol 16(5):1435-1437

Abellan P, Sanchez-Fernandez D, Velasco J, Millan A (2005) Conservation of freshwater biodiversity: a comparison of different area selection methods. Biodivers Conserv 14:3457-3474

Allan JD, Flecker AS (1993) Biodiversity conservation in running waters. Biosciences 43(1):32-43

Aronson J, Clewell AF, Blignaut JN, Milton SJ (2006) Ecological restoration: A new frontier for nature conservation and economics. J Nat Conserv 14:135-139

Baisez A, Laffaille P (2005) Un outil d'aide à la gestion de l'anguille : le tableau de bord anguille du bassin Loire. Bull Fr Pêche Piscicole 378-379:115-130

Canard A, Ysnel F (2000) Practical use of a single index to estimate the global range of rarity spider communities in western France. European Arachnology, Aarhus University Press, pp 171-176

Carwardine J, Rochester WA, Richardson KS, Williams KJ, Pressey RL, Possingham HP (2007) Conservation planning with irreplaceability : does the method matter? Biodivers Conserv 16:245-258

Chovanec A, Hofer R, Schiemer F (2003) Fish as bioindicators. In: Markert BA, Breure AM, Zechmeiser HG (eds) Bioindicators and biomonitors, pp 639-675

Collares-Pereira MJ, Cowx IG (2004) The role of catchment scale environmental management in freshwater fish conservation. Fish Manag Ecol 11:302-312

Copp GH, Bianco PG, Bogutskaya NG, Eros T, Falka I, Ferreira MT, Fox MG, Freyhof J, Gozlan RE, Grabowska J, Kovac V, Moreno-Amich R, Naseka AM, Penaz M, Povz M, Przybylski M, Robillard M, Russell IC, Stakenas S, Sumer S, Vila-Gispert A, Wiesner C (2005) To be, or not to be, a non-native freshwater fish? J Appl Ichtyol 21:242-262

Cuizhang F, Jihua W, Jiakuan C, Qianhong W, Guangchun L (2003) Freshwater fish biodiversity in the Yangtze river basin of China: patterns, threats and conservation. Biodivers Conserv 12:1649-1685

Darwall WRT, Vié JC (2005) Identifying important sites for conservation of freshwater biodiversity: extending the species-based approach. Fish Manag Ecol 12:287-293

Das A, Krishnaswamy J, Bawa KS, Kiran MC, Srinivas V, Kumar NS, Karanth KU (2006) Prioritisation of conservation areas in the Western Ghats, India. Biol Conserv 133:16-31

Dawson TP, Berry PM, Kampa E (2003) Climate change impacts on freshwater wetland habitats. J Nat Conserv 11:25-30

Dudgeon D, Arthington AH, Gessner MO, Kawabata ZI, Knowler DJ, Lévêque C, Naiman RJ, PrieurRichard AH, Soto D, Stiassny MLJ, Sullivan CA (2006) Freshwater biodiversity: importance, threats, status and conservation challenges. Biol Rev 81:163-182

Fattorini S (2006) A new method to identify important conservation areas applied to the butterflies of the Aegean Islands (Greece). Anim Conserv 9:75-83

Galat DL, Zweimüller I (2001) Conservation large-river fishes: is the highway analogy an appropriate paradigm? J North Am Benthol Soc 20:266-279

Gibbs JP (2000) Wetland loss and biodiversity conservation. Conserv Biol 14(1):314-317

Gotelli NJ, Colwell RK (2001) Quantifying biodiversity: procedures and pitfalls in the measurement and comparison of species richness. Ecol Lett 4:379-391

Guégan JF, Lek S, Oberdorff T (1998) Energy availability and habitat heterogeneity predict global riverine fish diversity. Nature 391:382-384

Heino J (2002) Concordance of species richness patterns among multiple freshwater taxa: a regional perspective. Biodivers Conserv 11:137-147

Hickley P, Chare S (2004) Fisheries for non-native species in England and Wales: angling or the environment? Fish Manag Ecol 11:203-212

Huet M (1959) Profiles and biology of western European streams as related to fish management. Trans Am Fish Soc 88:155-163

Ibarra A, Gevrey M, Park Y-S, Lim P, Sovan L (2003) Modelling the factors that influence fish guilds composition using a back-propagation network : assessment of metrics for indices of biotic integrity. Ecol Model 160:281-290 
Ibarra A, Parks Y-S, Brosse S, Reyol Y, Lim P, Lek S (2005) Nested patterns of spatial diversity revealed for fish assemblages in a west European river. Ecol Freshw Fish 14:233-242

Kondolf GM, Boulton AJ, O’Daniel S, Poole GC, Rachel FJ, Stanley EH, Wohl E, Bang A, Carlstrom J, Cristoni C, Huber H, Koljonen S, Louhi P, Nakamura K (2006) Process-based ecological river restoration: Visualizing three-dimensional connectivity and dynamic vectors to recover lost linkages. Ecol Soc 11:5

Laffaille P, Acou A, Guillouët J, Legault A (2005) Temporal changes in European eel, Anguilla anguilla, stocks in a small catchment after installation of fish passes. Fish Manag Ecol 12:123-129

Lasne E, Bergerot B, Lek S, Laffaille P (2007a) Fish zonation and indicator species for the evaluation of the ecological status of rivers: example of the Loire Basin (France). River Res Appl 23:877-890

Lasne E, Lek S, Laffaille P (2007b) Patterns in fish assemblages in the Loire floodplain: The role of hydrological connectivity and implication for conservation. Biol Conserv 139:258-268

Lévêque C, Balian EV, Martens K (2005) An assessment of animal species diversity in continental waters. Hydrobiologia 542:39-67

Lima-Junior SE, Cardone IB, Goitein R (2006) Fish assemblage structure and aquatic pollution in a Brazilian stream: some limitation of diversity indices and models for environmental impact studies. Ecol Freshw Fish 15:284-290

Lytle DA, Poff NL (2004) Adaptation to natural flow regimes. Trends Ecol Evol 19:94-100

Maes D, Bauwens D, De Bruyn L, Anselin A, Vermeersch G, Van Landuyt W, De Knijf G, Gilbert M (2005) Species richness coincidence: conservation strategies based on predictive modelling. Biodivers Conserv 14:1345-1364

Manchester S, Bullock JM (2000) The impacts of non-native species on UK biodiversity and the effectiveness of control. J Appl Ecol 37:845-864

Margules CR, Pressey RL (2000) Systematic conservation planning. Nature 405:243-253

Myers N, Mittermeier RA, Mittermeier CG, Da Fonseca GAB, Kent J (2000) Biodiversity hotspots for conservation priorities. Nature 403:853-858

Noss RF (2000) High-risk ecosystems as foci for considering biodiversity and ecological integrity in ecological risk assessments. Environ Sci Policy 3:321-332

Oberdorff T, Guilbert E, Lucchetta J-C (1993) Patterns of fish species richness in the Seine River basin, France. Hydrobiologia 259:157-167

Oberdorff T, Guégan JF, Hugueny B (1995) Global scale patterns of fish species richness in rivers. Ecography 18:345-352

Oberdorff T, Pont D, Hugueny B, Chessel D (2001) A probabilistic model characterizing riverine fish communities of French rivers : a framework for environmental assessment. Freshw Biol 46:399-415

Oberdorff T, Pont D, Hugueny B, Porcher JP (2002) Development and validation of a fish-based index (FBI) for the assessment of "river health" in France. Freshw Biol 47:1720-1734

Pawar S, Koo MS, Kelley C, Ahmed MF, Chaudhuri S, Sarkar S (2007) Conservation assessment and prioritization of areas in Northeast India: priorities for amphibians and reptiles. Biol Conserv. (in press) doi:10.1016/j.biocon.2006.12.012

Poff NL, Allan JD, Bain MB, Karr JR, Prestegaard KL, Richter BD, Sparks RE, Stromberg JC (1997) The natural flow regime : a paradigm for river conservation and restoration. BioScience 47:769-784

Pringle C (2001) Hydrologic connectivity and the management of Biological reserves: a global perspective. Ecol Appl 11:981-998

Quist MC, Rahel FJ, Hubert WA (2005) Hierarchical faunal filters: an approach to assessing effects of habitat and nonnative species on native fishes. Ecol Freshw Fish 14:24-39

Ricciardi A, Rasmussen JB (1999) Extinction rate of North America freshwater fauna. Conserv Biol 13(5):1220-1222

Saunders DL, Meeuwig JJ, Vincent ACJ (2002) Freshwater protected areas: strategies for conservation. Conserv Biol 16(1):30-41

Seegert G (2000) Considerations regarding development of index of biotic integrity metrics for large rivers. Environ Sci Policy 3:99-106

Sólymos P, Fehér Z (2005) Conservation prioritization based on distribution of land snails in Hungary. Conserv Biol 19(4):1084-1094

Szöllosi-Nagy A, Najilis P, Björklund G (1998) Assessing the world's freshwater resources. Nat Resour $34: 8-18$

Tetzlaff D, Soulsby C, Bacon PJ, Youngson AF, Gibbins C, Malcolm IA (2007) Connectivity between landscapes and riverscapes: a unifying theme in integrating hydrology and ecology in catchment science? Hydrol Processes 21:1385-1389

Turpie JK (1995) Prioritizing South African estuaries for conservation: A practical example using waterbirds. Biol Conserv 74:175-185 
Verneaux J (1981) Fish and the quality of streams. An Sci Univ F Comté biol Anim 4(2):33-41

Welcomme RL, Winemiller KO, Cowx IG (2006) Fish environmental guilds as a tool for assessment of ecological condition of river. River Res Appl 22:377-396

Ward JV, Tockner K, Uehlinger U, Malard F (2001) Understanding natural patterns and processes in river corridors as the basis for effective river restoration. Regul Rivers Res Manag 17:311-323

Ward JV (1998) Riverine landscapes: biodiversity patterns, disturbance regimes, and aquatic conservation. Biol Conserv 83:269-278

Williams P, Gibbons D, Margules C, Rebelo A, Humphries C, Pressey R (1996) A comparison of richness hotspots, rarity hotspots, and complementary areas for conserving diversity of British birds. Conserv Biol 10(1):155-174

Young TP (2000) Restoration ecology and conservation biology. Biol Conserv 92:73-83 